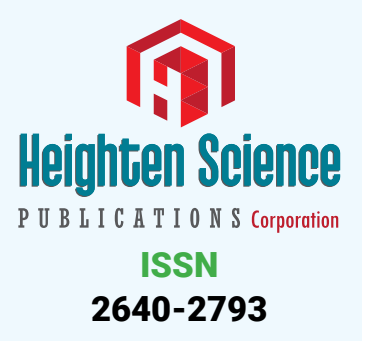

*Address for Correspondence: Dr. KP Mishra, Scientist 'E'; O/o Director General (Life Sciences), Defence Research and Development Organization, New Delhi - 110011, India, Tel. +91 11 23007342; Fax: +91 11 23017582; Email:kpmpgi@rediffmail.com

Submitted: 30 September 2018

Approved: 12 October 2018

Published: 15 October 2018

Copyright: ๑ 2018 Mishra KP, et al. This is an open access article distributed under the Creative Commons Attribution License, which permits unrestricted use, distribution, and reproduction in any medium, provided the original work is properly cited

Check for updates
Editorial

\section{Endogenous Ligands of Toll Like Receptors: A Danger Signal to the Brain Memory at High Altitude}

\author{
KP Mishra* and Shashi Bala Singh \\ Defence Institute of Physiology and Allied Sciences (DIPAS, DRDO)New Delhi - 110011, India
}

\section{Editorial}

Sojourn to high altitude may affect various human systems if proper acclimatization not followed. If acclimatization failed, sojourners may suffer with high altitude sickness such as acute mountain sickness (AMS), high altitude pulmonary edema (HAPE) and high altitude cerebral edema (HACE). Although a sojourner's tolerance to high altitude hypoxia varies according to differences in physiology and physical conditioning. Acute mountain sickness may cause headache, insomnia, dizziness, nausea, vomiting and fatigue. While HACE is more serious stage where brain swelling occurs and it is potentially fatal. A sojourner with HACE may experience confusion, amnesia, delusions, and loss of consciousness. Staying in high altitude (above 9000 feet) environment poses low oxygen supply (hypobaric hypoxia) to the different body organs including brain.

Brain is the organ that reacts sensitively to oxygen deprivation, which leads to inflammation, oxidative stress and cognitive function impairment. Our previous studies have reported that exposure to hypoxia leads to neurodegeneration and memory impairment also hypoxia exposure upregulated NALP3 mediated IL-1 beta and NF-kB expression [1-3]. Recently our laboratory has reported that suppression of scavenger receptor Mac-1 attenuates microglial phenotype switching and working memory impairment following hypoxia [4].

Brain has resident macrophages known as Glial cells which expresses Toll Like Receptors (TLRs). There are two groups of TLRs -(i) TLRs 1, 2, 4, 5 and 6 are expressed on the cell surface (ii) TLRs 3, 7, 8 and 9 are expressed intracellularly on endosomal membranes. TLRs 3, 4, 5, 7 and 9 are signal through their homodimer while TLR2 may dimerize with TLR1 or 6 depending on the ligand.

TLR-4 signaling occurs by the binding of endogenous ligands such as high mobility group box -1 (HMGB-1), stress proteins like Hsp60 and Hsp70. These endogenous ligands up-regulated during high altitude sojourn. Finally, they bound to their receptors such as TLR-4, which in downstream signaling cascade up-regulate proinflammatory mediators like TNF-alpha and interlukin-1 beta and proinflammatory chemokines by activation of transcription factor NF-kB $[5,6]$. The increased level of TNF-alpha upregulate apoptosis of the brain cells in different regions such as Hippocampus and prefrontal cortex. The loss of brain cells due to apoptosis may be the cause of memory impairment at high altitude.

Furthermore, our previous study reported that hypoxic preconditioning of mammalian cells has beneficial effects against hypoxic injuries [7]. However, very little information is available on the use of hypoxia mimetic on brain and high altitude induced memory loss. 
In one of our study, Das et al. [2], has shown that hypobaric hypoxia induces working memory impairment. Study reported that endogenous ligand HMGB1 get upregulated in Rats' brain when exposed to hypobaric hypoxia while treatment with andrographolide an active constituents of a plant Andrographis paniculata inhibit the expressions of HMGB1. The decreased expression HMGB1 leads to decreased expression of NF-kB and secretion of pro-inflammatory cytokines, therefore decreased apoptosis.

Thus, neuroinflammation induced neurodegeneration may be prevented by the use of andrographolide. In conclusion, endogenous ligands of TLRs could be important therapeutic target for prevention of high altitude induced memory impairment.

\section{References}

1. Das S, Mishra KP, Ganju L, Singh SB. Andrographolide - A promising therapeutic agent, negatively regulates glial cell derived neurodegeneration of prefrontal cortex, hippocampus and working memory impairment. J Neuroimmunol. 2017; 313: 161-175. Ref.: https://goo.gl/yqePWR

2. Das S, Mishra KP, Ganju L, Singh SB. Intranasally delivered small interfering RNA-mediated suppression of scavenger receptor Mac-1 attenuates microglial phenotype switching and working memory impairment following hypoxia. Neuropharmacology. 2018; 137: 240-255. Ref.: https://goo.gl/mvJsFp

3. Khanna K, Mishra KP, Ganju L, Kumar B, Singh SB. High-Altitude-Induced alterations in Gut-Immune Axis: A review. Int Rev Immunol. 2018; 37: 119-126. Ref.: https://goo.gl/2rFgaj

4. Kumar R, Jain V, Kushwah N, Dheer A, Mishra KP, et al. Role of DNA Methylation in Hypobaric Hypoxia-Induced Neurodegeneration and Spatial Memory Impairment. Ann Neurosci 2018; 25: 191200. Ref.: https://goo.gl/v9MYdr

5. Mishra KP, Ganju L, Singh SB. Hypoxia modulates innate immune factors: A review. Int Immunopharmacol. 2015; 28: 425-428. https://goo.gl/Z2cC38

6. Mishra KP, Sharma N, Soree P, Gupta RK, Ganju L, Singh SB. Hypoxia-Induced Inflammatory Chemokines in Subjects with a History of High-Altitude Pulmonary Edema. Indian J Clin Biochem. 2016; 31: 81-86. Ref.: https://goo.gl/A2zWC7

7. Shweta, Mishra KP, Chanda S, Singh SB, Ganju L. A comparative immunological analysis of $\mathrm{CoCl} 2$ treated cells with in vitro hypoxic exposure. Biometals. 2015; 28: 175-185. Ref.: https://goo.gl/x9sMwC 